\title{
Enhancing Skin Permeation of Biphenylacetic Acid (BPA) Using Salt Formation with Organic and Alkali Metal Bases
}

\author{
Vijay PaWAR, Prashant NaIK, Rajani GIRIDHAR, Mange Ram YADAV *
}

Pharmacy Department, Faculty of Technology \& Engineering, The M. S. University of Baroda, Vadodara390001, India.

* Corresponding author. E-mail: mryadav11@yahoo.co.in (M. R. Yadav)

Sci Pharm. 2015; 83: 191-205

doi:10.3797/scipharm.1406-19

Published: September $26^{\text {th }} 2014 \quad$ Received: June $30^{\text {th }} 2014$

Accepted: $\quad$ September $26^{\text {th }} 2014$

This article is available from: http://dx.doi.org/10.3797/scipharm.1406-19

(c) Pawar et al.; licensee Österreichische Apotheker-Verlagsgesellschaft m. b. H., Vienna, Austria.

This is an Open Access article distributed under the terms of the Creative Commons Attribution License (http://creativecommons.org/licenses/by/3.0/), which permits unrestricted use, distribution, and reproduction in any medium, provided the original work is properly cited.

\begin{abstract}
In the present study, a series of organic and alkali metal salts of biphenylacetic acid (BPA) have been prepared and evaluated in vitro for percutaneous drug delivery. The physicochemical properties of BPA salts were determined using solubility measurements, DSC, and IR. The DSC thermogram and FTIR spectra confirmed the salt formation with organic and alkali metal bases. Among the series, salts with organic amines (ethanolamine, diethanolamine, triethanolamine, and diethylamine) had lowered melting points while the alkali metal salt (sodium) had a higher melting point than BPA. The in vitro study showed that salt formation improves the physicochemical properties of BPA, leading to improved permeability through the skin. Amongst all the prepared salts, ethanolamine salt (1) showed 7.2- and 5.4-fold higher skin permeation than the parent drug at $\mathrm{pH} 7.4$ and 5.0, respectively, using rat skin.
\end{abstract}

\section{Keywords}

BPA • Lipophilicity $\bullet$ NSAID $・$ Salt $・$ Skin permeation

\section{Introduction}

Arthritis is a form of joint disorder involving inflammation, pain, and swelling of one or more joints. NSAIDs are commonly used to treat various forms of arthritis such as rheumatoid arthritis (RA) and osteoarthritis (OA). However, long-term systemic use of NSAIDs is often limited by a wide range of adverse events. The extensive use of oral NSAIDs results in 
gastrointestinal, cardiovascular, and renal adverse effects [1-5]. In rheumatic disorders, the percutaneous delivery of drugs to the underlying muscle and joint tissues is of considerable importance. Hence, a potential way to mitigate the side effects of orally administered NSAIDs is their topical application [6]. The clinical efficacy of a topical NSAID preparation has been confirmed in patients with a variety of painful disorders [7]. Pharmacokinetic data of commercially available diclofenac sodium $1 \%$ gel (Voltaren; Novartis) show that compared to the oral diclofenac, topical diclofenac sodium (1\% gel) produces lower mean plasma concentration and minimizes the inherent side effects [8].

Percutaneous drug delivery allows the localization of the drug at the target site [9]. The rate of transport across the skin depends on both the nature of the solute and the nature of the vehicle [10]. However, due to the unfavorable physicochemical properties of NSAIDs and the hindrance posed by skin barriers, the majority of the topically applied NSAIDs have low permeability through human skin [11]. The main driving force for the development of topical agents has been the potential avoidance of adverse reactions associated with systemic agents, increased concentration of the active moiety at the site of application, and other advantages such as the ease of application and termination of the therapy. Studies have confirmed that most of the drug present in the muscle and skin is due to direct migration and not from systemic circulation following topical application $[6,12]$.

Various strategies have been developed and used to improve the percutaneous delivery of NSAIDs that include the formulation approach, pro-drug approach, and salt formation [13-15]. In the formulation approach, penetration enhancers have been used to improve skin permeability. These penetration enhancers partition into the skin, interact with the constituents of the skin layers, and reduce the resistance of the skin to drug diffusion $[16,17]$. They may cause skin irritation and other side effects. The pro-drug approach has been used increasingly to improve the delivery of drugs through the skin and involves the modification of the basic structure of a drug; however, a high pro-drug concentration in the skin may lead to enzyme saturation kinetics and as a result, limited conversion of the prodrug to the parent drug might occur [18-21].

Salts are usually considered as alternatives for the delivery of a drug when the parent drug molecule is unsuitable for a formulation. This strategy enhances the transportation of the ionic drugs through the skin without modifying the molecular structure of the drug [22, 23]. It has been observed that biphenylacetic acid (BPA) has severe GIT side effects with oral administration due to its free carboxylic acid group that restricts its oral use [24]. Studies demonstrated that plasma levels of BPA following topical application were low and well below the reported therapeutic concentration of BPA [25]. This indicates that BPA is slowly absorbed into the bloodstream and has low permeability through the skin. The choice of the most appropriate drug for percutaneous delivery depends on a number of factors that include its potency, half-life, permeability, lack of local skin toxicity, etc. [26, 27]. In a recent study, nine commercially available topical NSAID preparations from the European Union have been studied for skin permeability, anti-inflammatory, and analgesic actions. This study revealed that the topical ketoprofen preparation showed superior results as compared to the other preparations [28]. From this study we can conclude that along with permeation enhancement, the pharmacokinetic and pharmacodynamic properties of NSAIDs are also important parameters from the therapeutic point of view for rheumatic diseases. For the safe and effective treatment of osteoarthritis (OA), the current new 
guidelines also recommended the use of topical NSAIDs, but the majority of the clinically used NSAIDs have short half-lives, low permeability, and lack affinity to the joint cavity which adversely affects the treatment of rheumatic diseases [8].

In the present study we have prepared various salts of BPA, an active metabolite of fenbufen, which is twice as active as the parent drug, having a long half-life $(>10 \mathrm{~h})$ and proven to be compatible and safe for topical application [25, 29]. Based on these favorable pharmacokinetic and pharmacodynamic properties, we synthesized and evaluated the salts of BPA to improve the skin permeability of BPA. For the synthesis of salts, various organic and alkali metal bases such as ethanolamine, diethanolamine, triethanolamine, diethylamine, and sodium hydroxide have been used and the differences between the physicochemical characteristics of BPA and its salts have been evaluated by using DSC, FTIR, SEM, etc. The effect of salt formation on percutaneous absorption has been investigated in vitro using skin from the whole dorsal area of a male Wistar rat.

\section{Results and Discussion}

\section{Syntheses of BPA Salts}

BPA (1), required for the synthesis of the salts, was prepared by the reported procedure [31]. In the current study, due to the presence of the acidic functional group in BPA, we prepared some salts of this NSAID with organic and alkali metal bases. Alkanolamines such as ethanolamine, diethanolamine, triethanolamine, and diethylamine (DEA) have been chosen for this purpose because these alkanolamines are weak bases. The amino group will react with the acidic carboxylic acid group present in the BPA resulting in salt formation. Structures of the prepared salts are shown in Fig. 1.

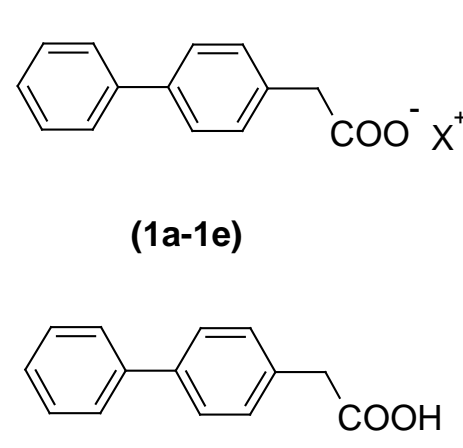

(1)

$$
\begin{gathered}
\frac{\mathrm{X}^{+}=}{\mathrm{a}^{+}} \\
+ \\
\text {b: } \mathrm{H}_{3} \mathrm{~N}-\mathrm{CH}_{2} \mathrm{CH}_{2} \mathrm{OH} \\
+ \\
\text { c: } \mathrm{H}_{2} \mathrm{~N}\left(\mathrm{CH}_{2} \mathrm{CH}_{2} \mathrm{OH}\right)_{2} \\
+ \\
\text { d: } \stackrel{\mathrm{HN}\left(\mathrm{CH}_{2} \mathrm{CH}_{2} \mathrm{OH}\right)_{3}}{ } \\
+\underset{+}{\text { e: } \mathrm{HN}\left(\mathrm{CH}_{2} \mathrm{CH}_{3}\right)_{2}}
\end{gathered}
$$

Fig. 1. The structures of BPA (1) and its salts (1a-e)

\section{Characterization of Salts}

The prepared salts have been confirmed by various techniques such as FTIR, NMR, DSC, and SEM, which have been used to characterize the surface morphology of the prepared salts. The physicochemical and spectral data of the compounds are listed in Table 1. 
The prepared salts were characterized by using IR. The FTIR spectra of BPA (1) and its salts are shown in Fig. 2. As expected, the obvious difference between the spectra of BPA and its salts was found in the $\mathrm{O}-\mathrm{H}$ and $\mathrm{N}-\mathrm{H}$ stretching regions. Alkanolamine salts showed peaks in the range of $3263-3404 \mathrm{~cm}^{-1}$ due to $\mathrm{N}-\mathrm{H}$ stretchings which were absent in BPA (1). Other signs of interactions were reflected by the presence of a strong sharp signal around $1685 \mathrm{~cm}^{-1}$, characteristic of the carbonyl stretching vibrations. The carbonyl peak of the BPA in the salts was shifted due to the interaction between the negative charge on the oxygen of BPA (1) and the positive charge on the nitrogen atom of alkanolamines.

Tab. 1. Physicochemical and spectral data of compounds (1, 1a-e)

\begin{tabular}{|c|c|c|c|c|}
\hline Cpd. & $\begin{array}{l}\text { Physical } \\
\text { state }\end{array}$ & $\begin{array}{l}\text { Melting } \\
\text { point }\left({ }^{\circ} \mathrm{C}\right)\end{array}$ & $\begin{array}{c}\text { DSC } \\
\left.\text { (Endotherm }{ }^{\circ} \mathrm{C}\right)\end{array}$ & $\begin{array}{c}\mathrm{IR} \\
\left(\mathrm{cm}^{-1}\right)\end{array}$ \\
\hline 1 & White Solid & $163-165$ & 153.89 & $1685,1413,1249$ \\
\hline $1 a$ & White Solid & $>275$ & - & $1684,1557,1294$ \\
\hline $1 b$ & Yellow Solid & $116-119$ & 137.62 & $3263,1674,1391$ \\
\hline $1 \mathrm{c}$ & Semisolid & - & - & $3248,1679,1374$ \\
\hline $1 d$ & White Solid & $82-84$ & 87.91 & $3354,1681,1077$ \\
\hline $1 e$ & Semisolid & - & - & $3407,1699,1571$ \\
\hline
\end{tabular}

In the NMR spectrum, aromatic protons of BPA appeared at $\delta 7.88-7.28$ as a multiplet, methylene protons at $\delta 3.65$ as a singlet, and the acidic proton at $\delta 8.84$. In the case of the ethanolamine salt of BPA, the obvious difference was the presence of additional peaks at $\delta$ 3.62-3.60 and at $\delta 3.22-3.18$ as triplets for methylene protons of ethanolamine and a broad peak at $\delta 6.07$ due to the protons of the ammonium group. Fig. 4. shows DSC curves of BPA (1) and its salts (1a-e). Table 1 summarizes the melting points and endothermic peaks of BPA (1) and its salts (1a-e). The melting points of the salts decreased remarkably compared to the parent drug except for the sodium salt (1a) which showed a higher melting point. Shifts in melting points are indicative of salt formation.

The surface morphology of the compounds varied from each other and to evaluate this parameter, the SEM of the prepared salts was performed. From this study, it was concluded that each salt has a different surface morphology as shown in Fig. 3.

\section{Physicochemical Evaluation}

For the evaluation of various physicochemical parameters such as aqueous solubility, partition coefficient, and in vitro skin permeability, the HPLC method was developed, calibration curves for BPA (1) were plotted, and the linearity range was calculated. 


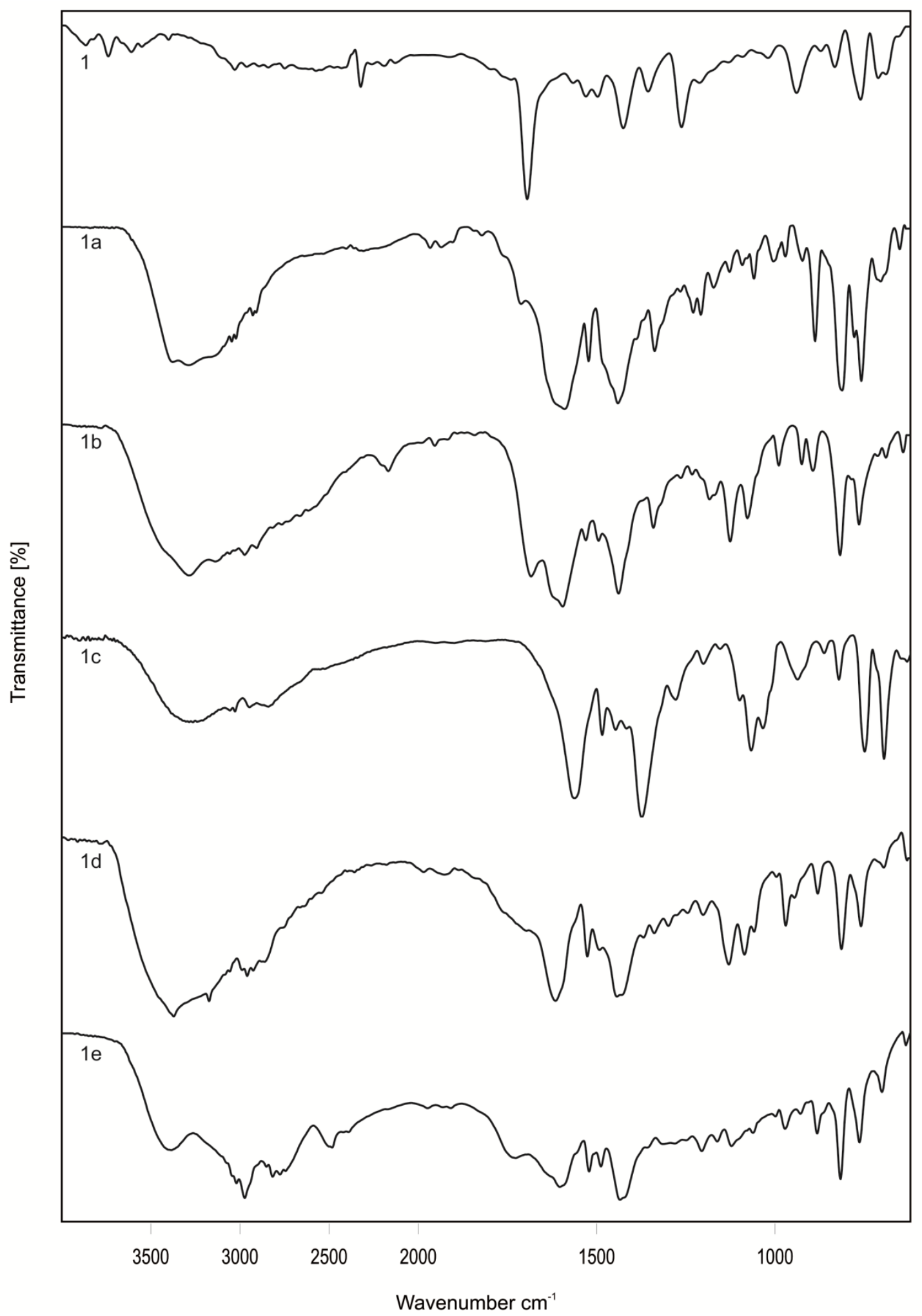

Fig. 2. FTIR Spectra of BPA (1) and its salts (1a-e) 


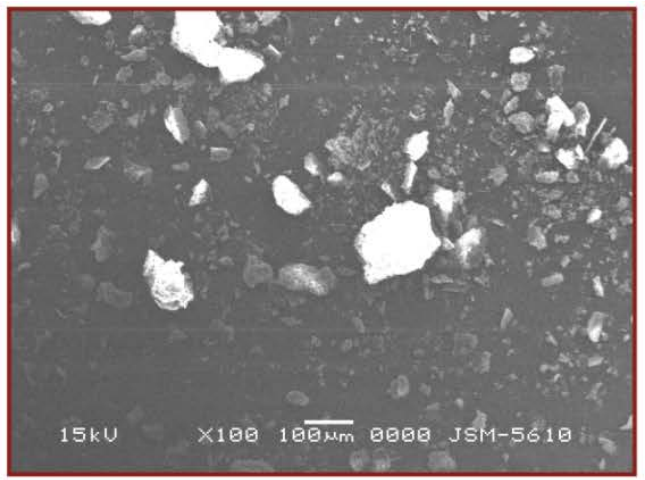

(1)
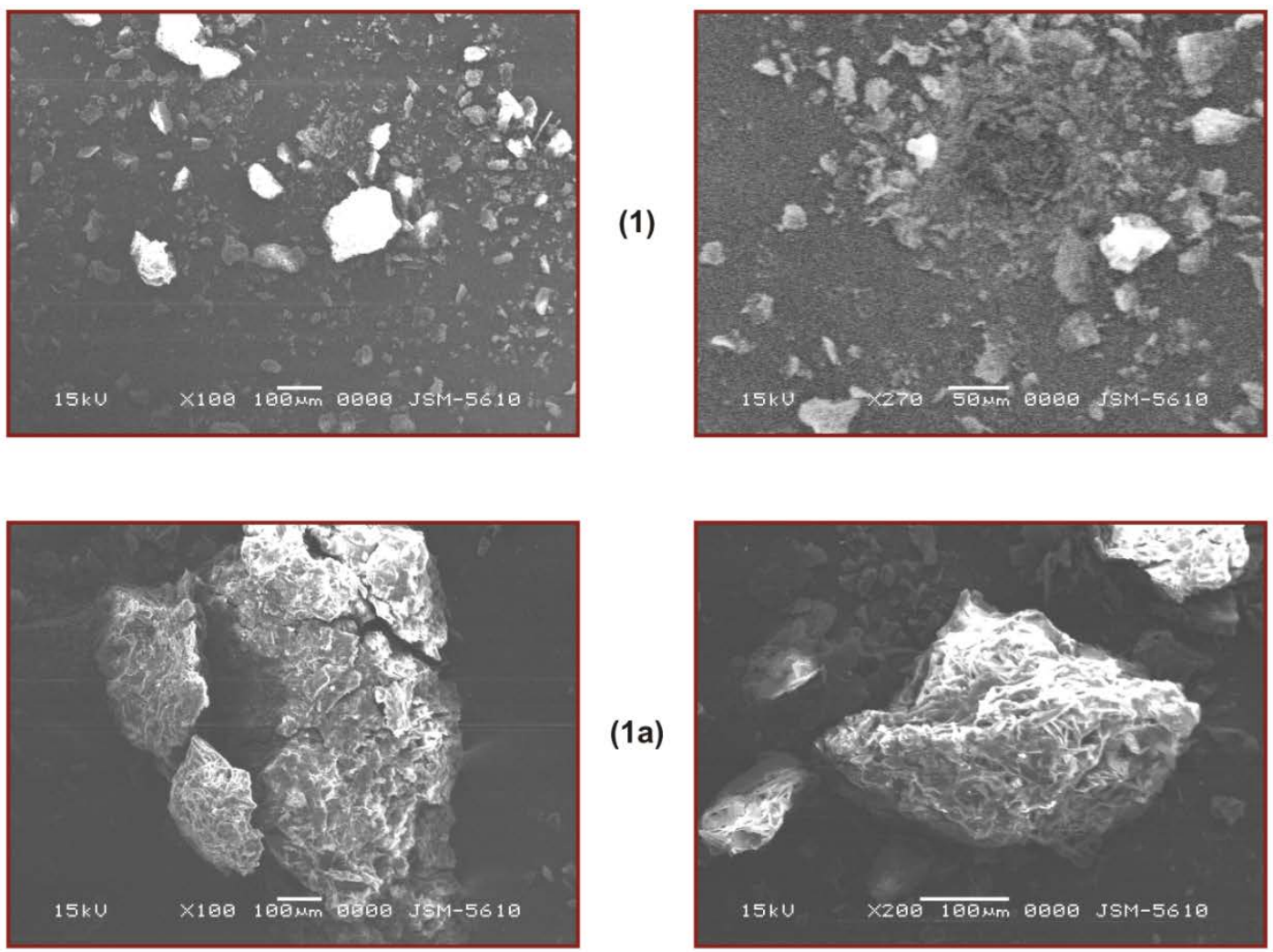

(1a)
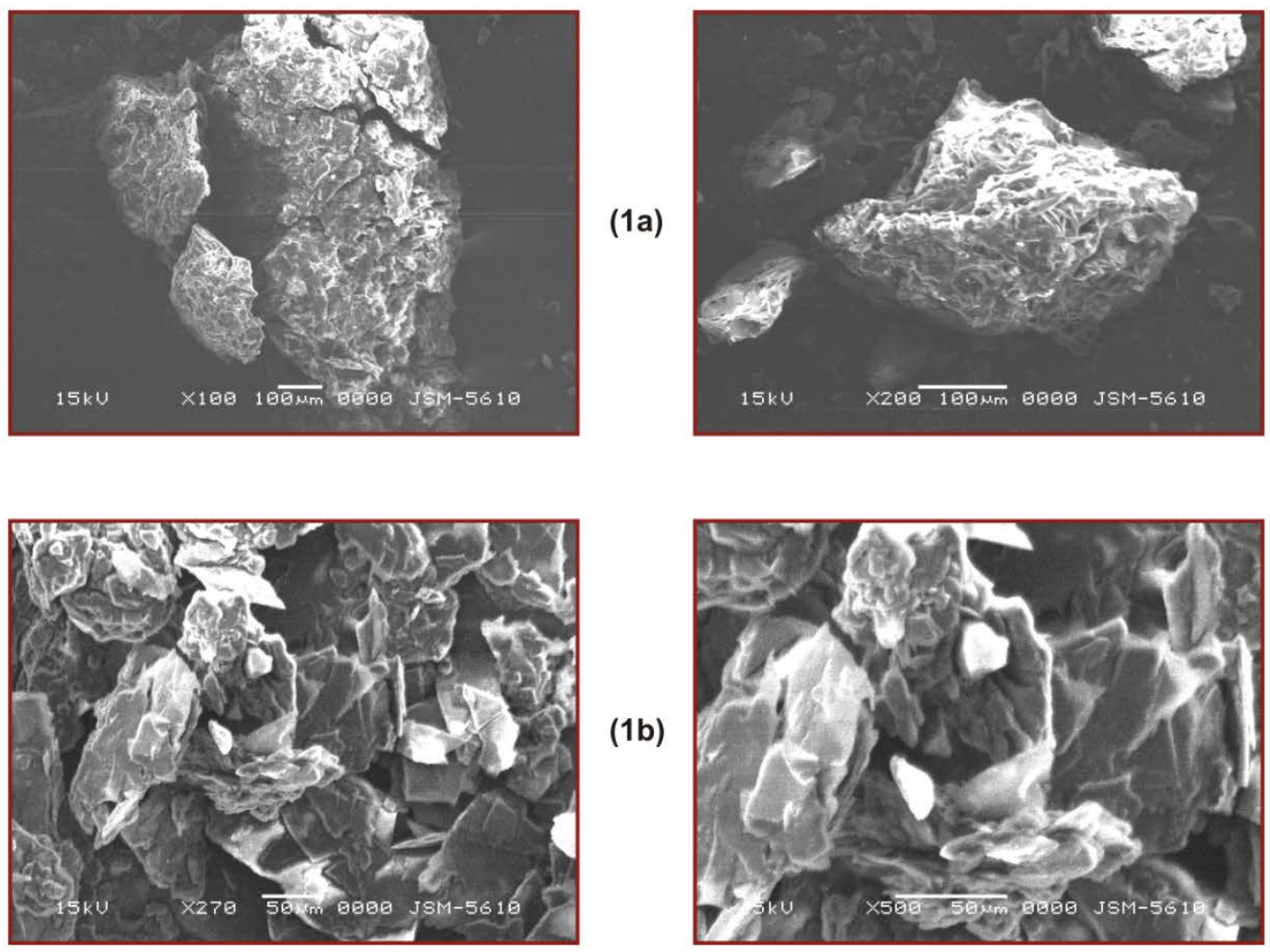

(1b)
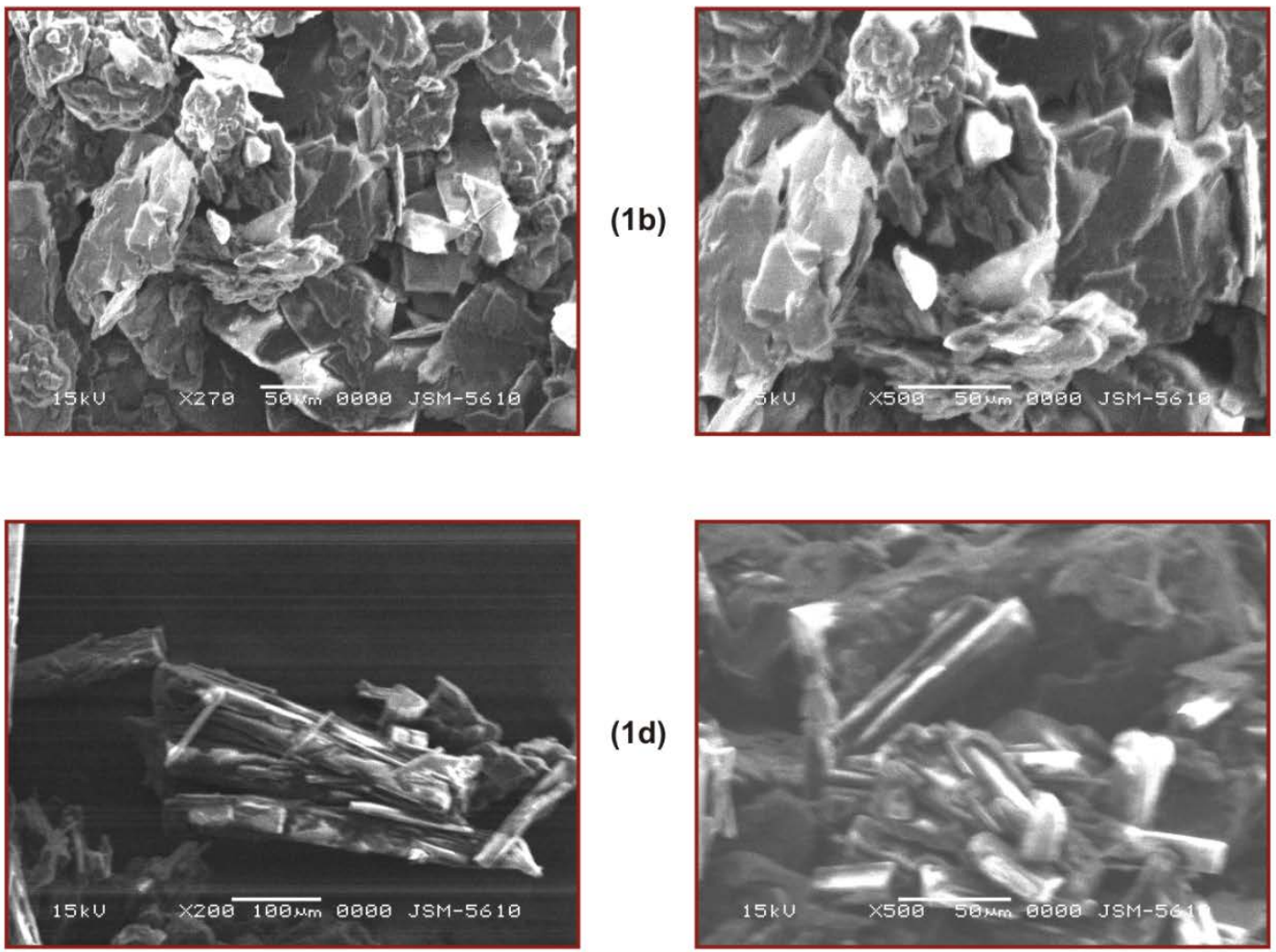

Fig. 3. Scanning electron microscope images of compounds (1, 1a, 1b, 1d) 


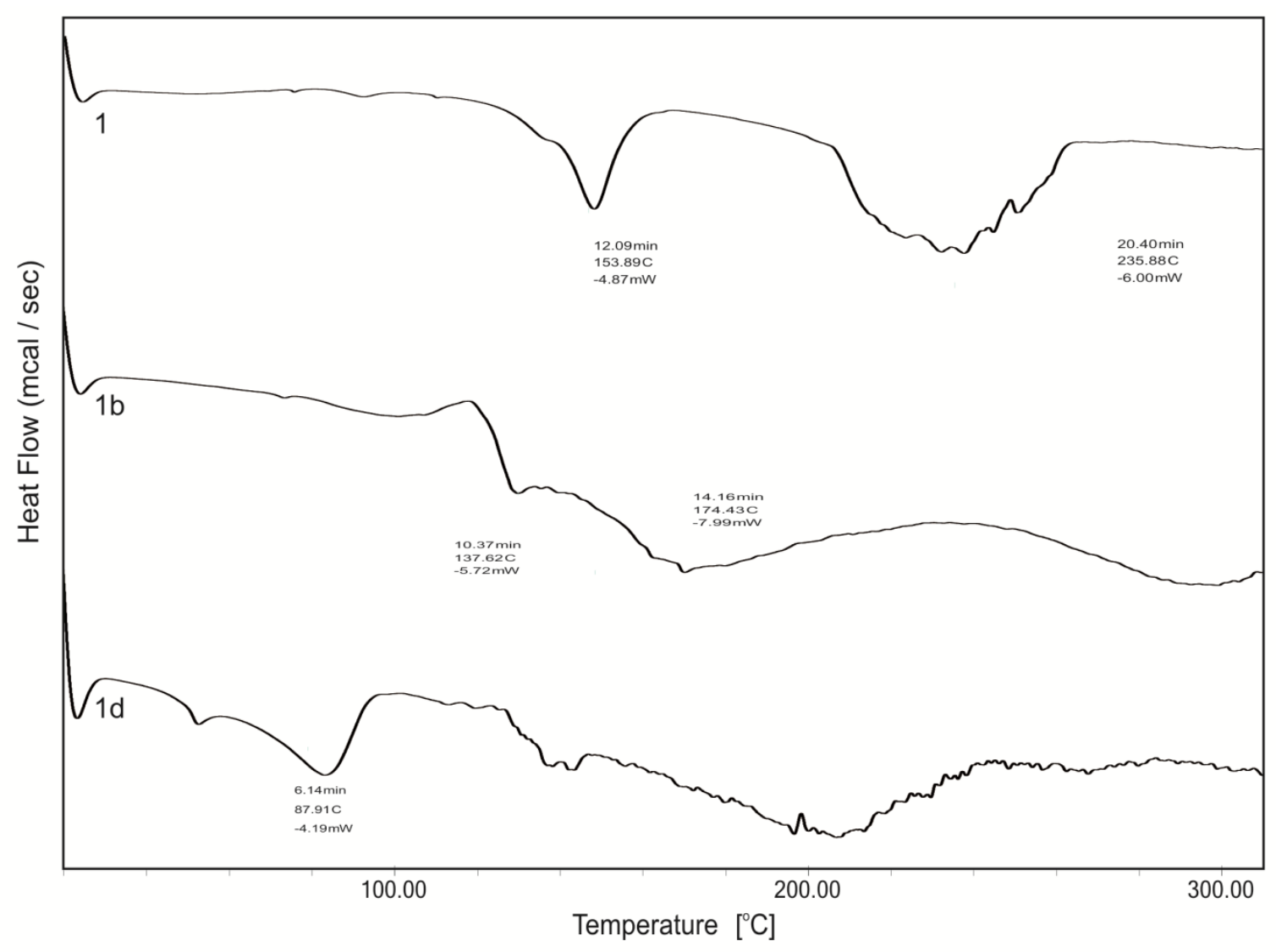

Fig. 4. DSC thermograms of BPA (1) and its salts (1b, 1d)

\section{Determination of Solubility in Phosphate Buffer}

Due to the biphasic nature of the skin, the ideal salt form should exhibit adequate lipid solubility as well as aqueous solubility. Aqueous solubility of BPA and its salts was determined in a phosphate buffer $(0.16 \mathrm{M})$ at the physiological $\mathrm{pH} 5.0$ and at $\mathrm{pH} 7.4$ as the environment of the outer surface of the skin is acidic $(\mathrm{pH} \mathrm{4.2-6.5)} \mathrm{[11];} \mathrm{the} \mathrm{values} \mathrm{are}$ given in Table 2. Fig. 5. shows the aqueous solubility of BPA (1) and its salts (1a-1e).

Tab. 2. Solubility and partition coefficient ( $\left.\log P_{\text {app }}\right)$ values of BPA (1) and its salts (1a-e) at $\mathrm{pH} 5.0$ and $\mathrm{pH} 7.4$

\begin{tabular}{lcccc}
\hline & \multicolumn{2}{c}{ Solubility in phosphate buffer } & \multicolumn{2}{c}{ Log $\boldsymbol{P}_{\text {app }}$} \\
\cline { 2 - 5 } Cpd. & $\mathbf{0 . 1 6} \mathbf{\text { M }}(\mathbf{m M})$ & $\mathbf{p H ~ 7 . 4}$ & $\mathbf{p H ~ 5 . 0}$ & $\mathbf{p H ~ 7 . 4}$ \\
\hline 1 & $0.57 \pm 0.14$ & $54.08 \pm 0.14$ & $1.20 \pm 0.06$ & $0.43 \pm 0.04$ \\
1a & $14.23 \pm 0.31$ & $17.05 \pm 0.21$ & $0.68 \pm 0.04$ & $0.50 \pm 0.05$ \\
1b & $28.96 \pm 0.28$ & $24.10 \pm 0.34$ & $2.04 \pm 0.04$ & $1.46 \pm 0.07$ \\
1c & $41.05 \pm 0.43$ & $37.08 \pm 0.33$ & $1.01 \pm 0.07$ & $0.91 \pm 0.03$ \\
1d & $24.27 \pm 0.22$ & $21.30 \pm 0.52$ & $1.20 \pm 0.04$ & $1.14 \pm 0.04$ \\
1e & $07.20 \pm 0.37$ & $05.18 \pm 0.45$ & $1.41 \pm 0.03$ & $1.01 \pm 0.09$ \\
\hline
\end{tabular}




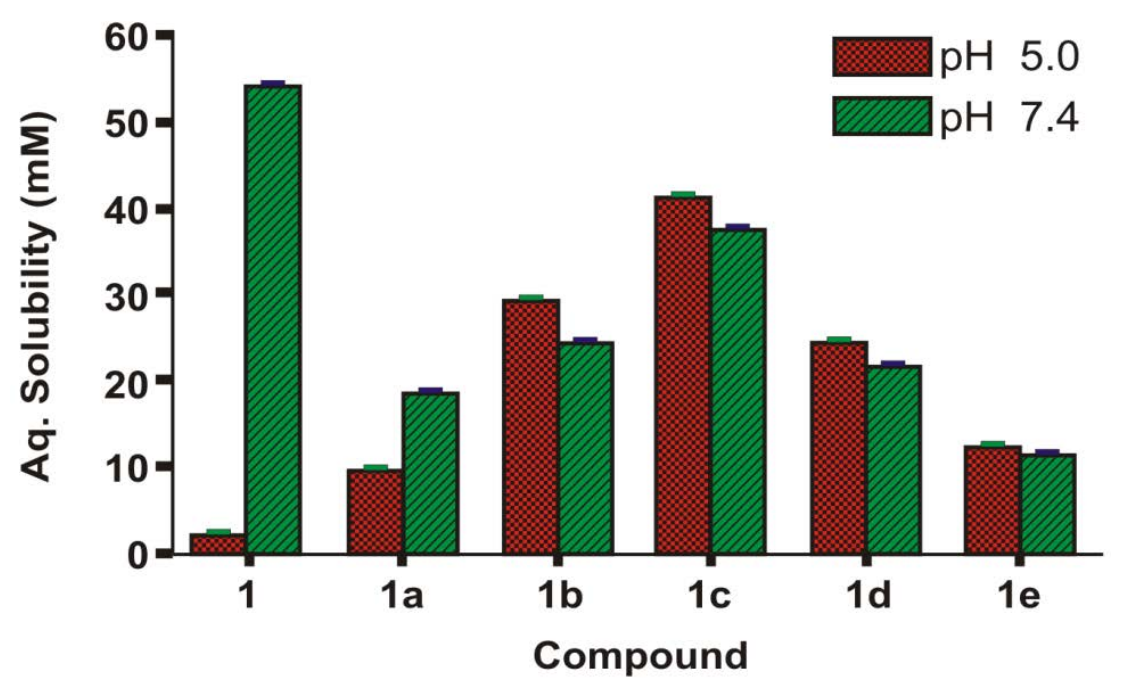

Fig. 5. Aqueous solubility of BPA (1) and its salts (1a-e)

\section{Determination of the Apparent Partition Coefficient (Log $P_{\text {app }}$ )}

Lipid solubility plays a crucial role in determining the skin permeability of a compound because the SC (stratum corneum), the major barrier to drug permeation, is essentially lipoidal in nature and generally favors the permeation of lipophilic drugs [11]. The apparent partition coefficients of BPA (1) and salts (1a-e) were determined by partitioning them between the phosphate buffer $(0.16 \mathrm{M})$ and 1-Octanol at both $\mathrm{pH} 5.0$ and $\mathrm{pH} 7.4$ by the shake flask method and are shown in Fig. 6. Table 2 shows the Log $P_{\text {app }}$ values of BPA (1) and its salts (1a-e).

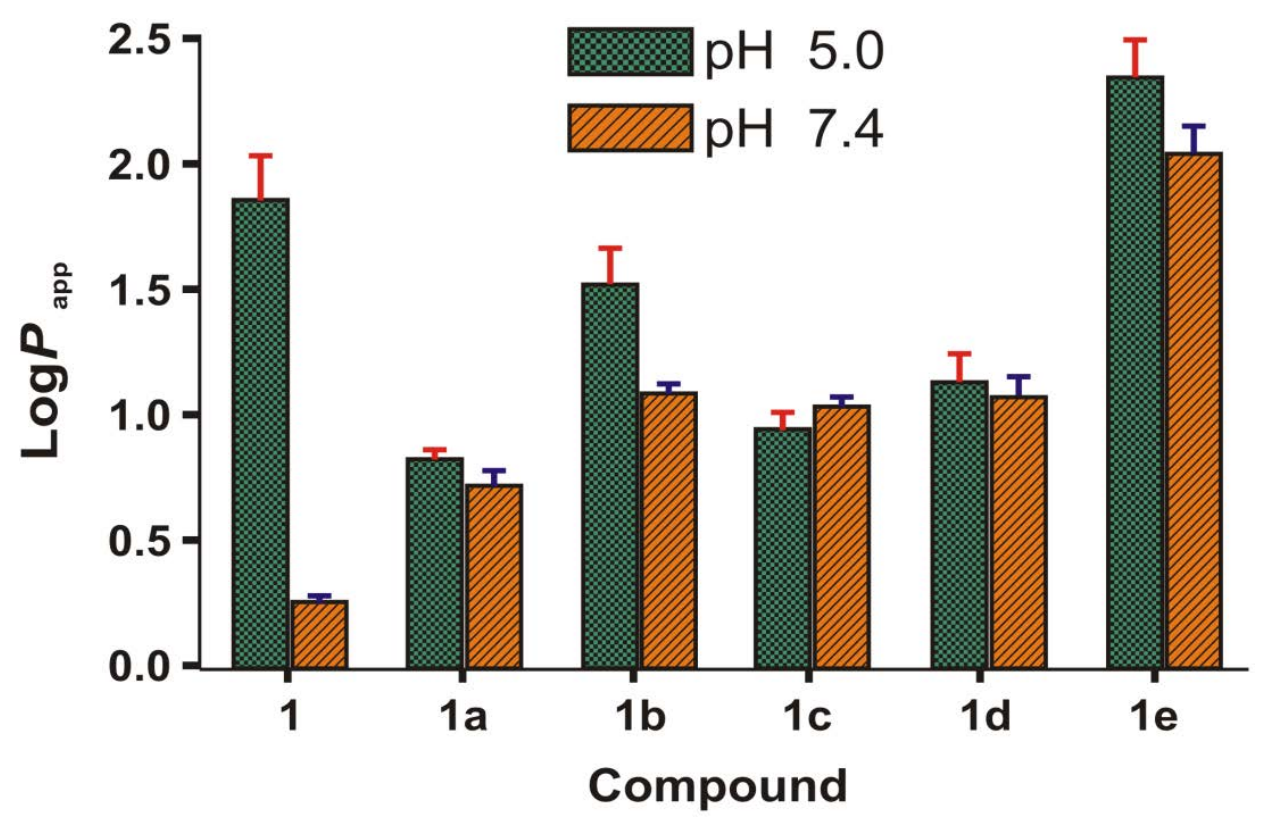

Fig. 6. Partition coefficient (Log $\left.P_{\text {app }}\right)$ values of BPA (1) and its salts (1a-e) 


\section{In Vitro Skin Permeation Study}

The in vitro skin permeation study was performed by using skin from the whole dorsal area of a male Wistar rat. The in vitro diffusion experiments showed that the salts of BPA were able to permeate skin. For each salt and the parent drug, the cumulative amounts permeated through the skin were plotted against time. A steady-state flux (Jss) was obtained by dividing the slope of that graph by the surface area of the diffusion cell (4.906 $\mathrm{cm}^{2}$ ) [11]. The steady-state flux (Jss) of BPA (1) and its salts (1a-e) is given in Table 3 . and shown in Fig. 7. All the salts have shown higher flux values than the parent NSAID and this is due to ion-pair formation. Amongst all the salts, $\mathbf{1 b}$ has shown the highest steady-state flux including BPA. The permeation profiles of BPA (1) and its salt (1) b) are shown in Fig. 8.

Tab. 3. Steady-state flux $\left(J_{\mathrm{ss}}\right)$ and permeability coefficients $\left(K_{\mathrm{p}}\right)$ of BPA $(\mathbf{1})$ and its salts $(1 \mathrm{a}-\mathrm{e})$

\begin{tabular}{lcccc}
\hline & \multicolumn{2}{c}{$\boldsymbol{K}_{\mathbf{p}} \mathbf{\times 1 \mathbf { 1 0 } ^ { \mathbf { 6 } }} \mathbf{( \mathbf { c m } / \mathbf { h } )}$} & \multicolumn{2}{c}{$\boldsymbol{J}_{\mathbf{s s}}\left(\mathbf{n . m o l} / \mathbf{c m}^{\mathbf{2}} . \mathbf{h}\right)$} \\
\cline { 2 - 5 } Cpd. & $\mathbf{p H ~ 5 . 0}$ & $\mathbf{p H ~ 7 . 4}$ & $\mathbf{p H ~ 5 . 0}$ & $\mathbf{p H ~ 7 . 4}$ \\
\hline 1 & $0.75 \pm 0.03$ & $0.03 \pm 0.01$ & $0.43 \pm 0.12$ & $2.15 \pm 0.18$ \\
1a & $0.12 \pm 0.01$ & $0.24 \pm 0.02$ & $1.75 \pm 0.14$ & $4.21 \pm 0.22$ \\
1b & $0.08 \pm 0.01$ & $0.64 \pm 0.04$ & $2.32 \pm 0.20$ & $15.47 \pm 0.34$ \\
1c & $0.06 \pm 0.01$ & $0.25 \pm 0.03$ & $2.76 \pm 0.21$ & $9.31 \pm 0.28$ \\
1d & $0.07 \pm 0.02$ & $0.27 \pm 0.02$ & $1.86 \pm 0.16$ & $5.79 \pm 0.19$ \\
1e & $0.22 \pm 0.02$ & $0.60 \pm 0.03$ & $1.59 \pm 0.11$ & $3.14 \pm 0.20$ \\
\hline
\end{tabular}

The ethanolamine salt displayed 7.2-times higher flux than the parent drug. The result also showed that the salts with higher flux have a balance between aqueous solubility and the partition coefficient. Further, except for the sodium salt, all the salts have shown lower melting points than the parent drug and higher permeability through the skin, which support previous reports, indicating that a decrease in melting point or conversion of solid state to liquid state improves the permeability of the drugs through the skin [12]. Further, we can conclude that the significant enhancement of the skin permeability of BPA is the result of salt formation or ion pairing which is in good agreement with previously published work $[22,23,30]$.

\section{Experimental}

All the reagents and solvents required for the syntheses were purified by general laboratory techniques before use. The purity of the compounds and completion of the reactions were monitored by thin layer chromatography (TLC) on silica gel plates $\left(60 \mathrm{~F}_{254}\right.$; Merck), visualized with ultraviolet light or iodine vapors. The yields reported here are unoptimized. Melting points were determined using a Veego make silicon oil bath-type melting point apparatus and are uncorrected. The IR spectra were recorded using the $\mathrm{KBr}$ disc method in $\mathrm{cm}^{-1}$ on a Bruker FTIR, Model 8300. The PMR spectra were recorded in $\mathrm{CDCl}_{3}$ on a Bruker $400 \mathrm{MHz}$ spectrometer (chemical shifts in $\delta \mathrm{ppm}$, coupling constant $J$ in $\mathrm{Hz}$ ). $\lambda_{\max }$ was determined on the Shimadzu 1800 UV spectrophotometer. The mass of the compounds was determined by LC-MS using electron impact as the source of ionization. DSC was performed on the Shimadzu DSC-60 model with the thermal analyser TA 60WS. 
The scanning electron microscope (SEM) model ESEM-EDAX XL-30, Philips (Netherlands) was used for the study of surface morphology. In vitro skin permeation studies were conducted using a Franz-type diffusion cell using skin from the whole dorsal area of a male Wistar rat $(200 \pm 10 \mathrm{~g})$. Animal experiments were performed with the approval of the institutional animal ethical committee (MSU/PHARM/IAEC/2011/14) in accordance with Laboratory Animal Welfare guidelines.

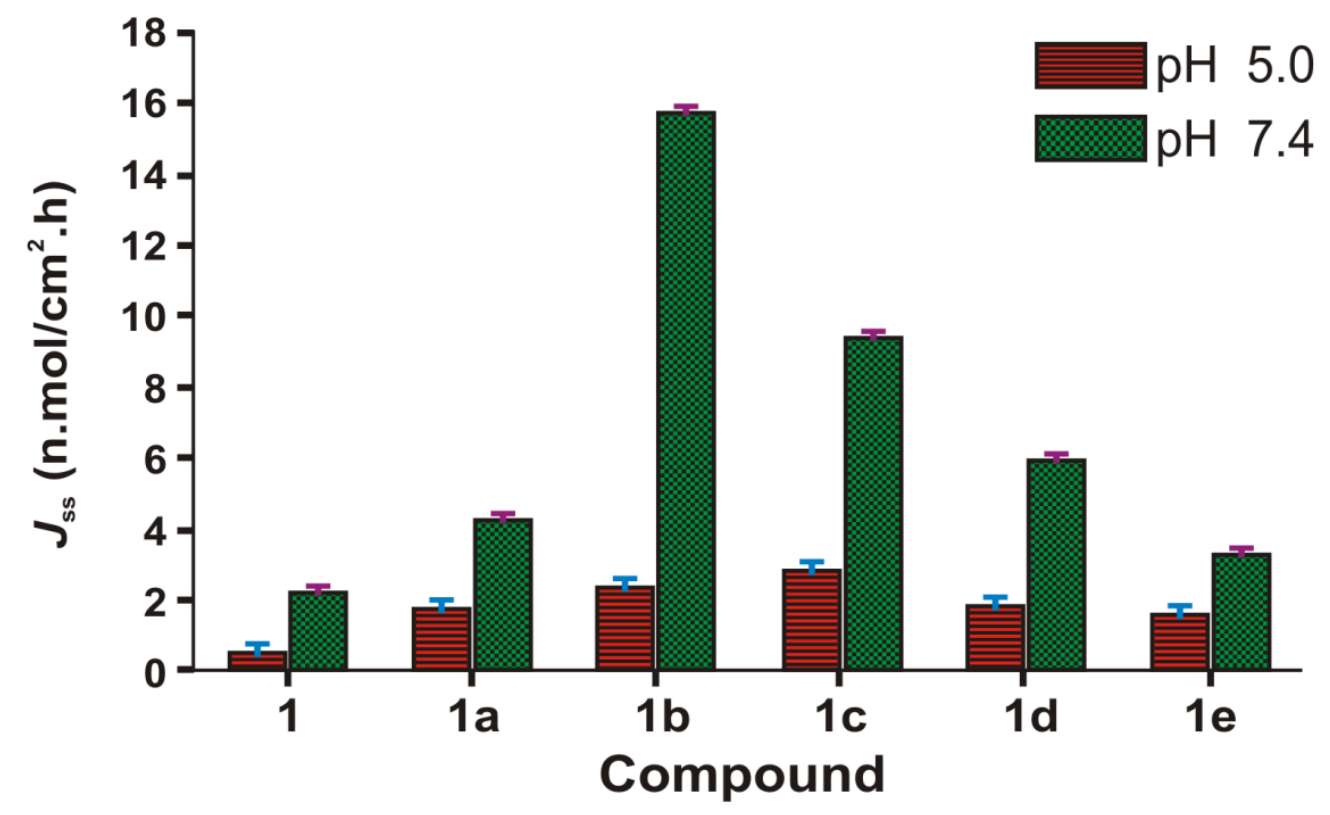

Fig. 7. Steady-state flux $\left(J_{\mathrm{ss}}\right)$ of 6-MNA (1) and the salts (1a-e) through rat skin in vitro at $37^{\circ} \mathrm{C}$

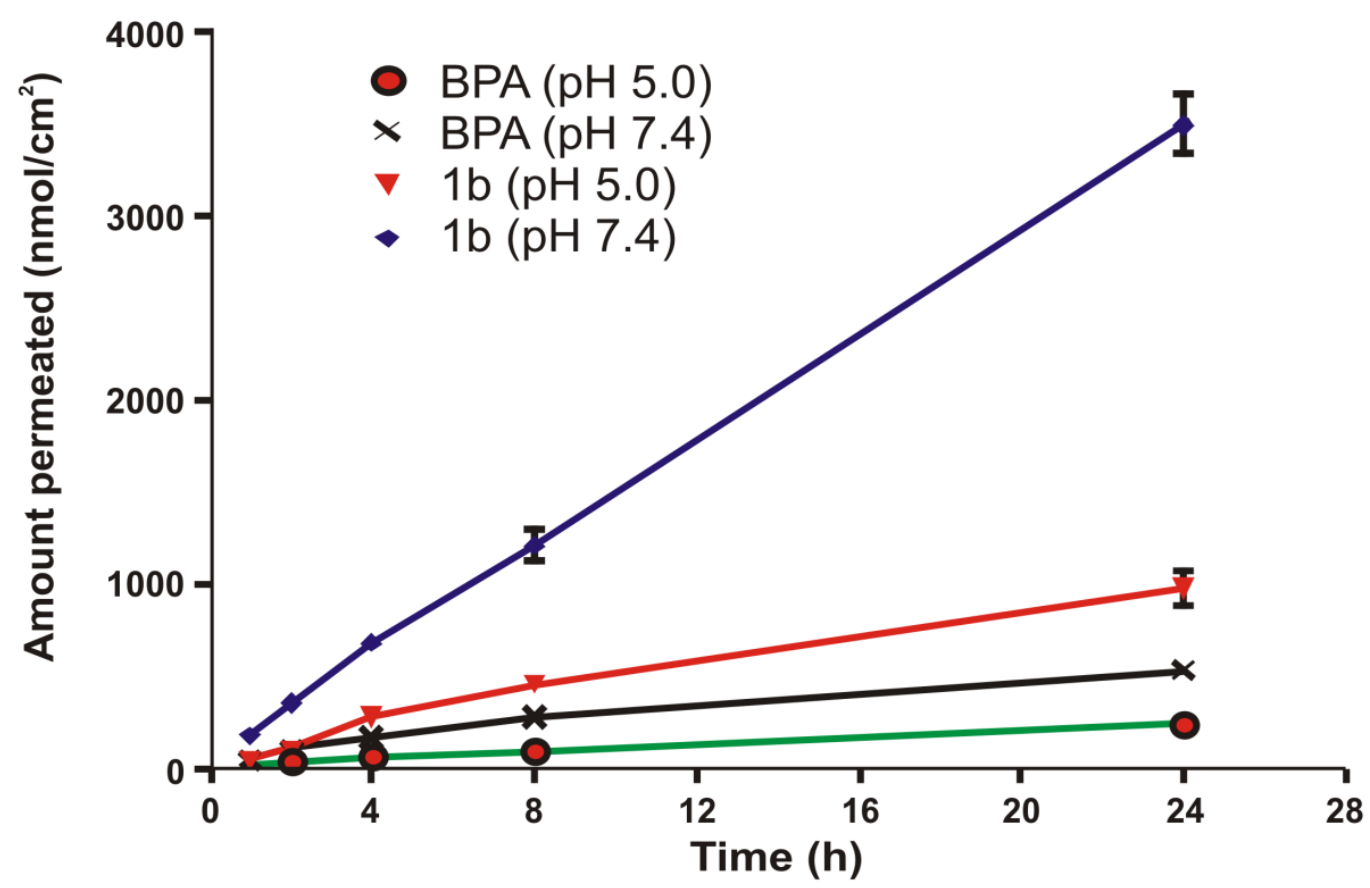

Fig. 8. Permeation profile of BPA (1) and its salt (1) (mean \pm SEM, n=3-6) at pH 5.0 and 7.4 


\section{Synthesis of Salts}

BPA (1), required for the synthesis of the salts, was prepared by the reported procedure [31]. BPA (1) was dissolved in dichloromethane with the help of a small amount of methanol to make the solution clear and an equimolar amount of base (alkanolamines or sodium hydroxide) was added and the reaction mixture was stirred for 5-6 $\mathrm{h}$. The precipitated salt was collected by filtration and recrystallized from ethyl acetate to yield pure salts (1a-e) of BPA.

\section{HPLC Analysis}

HPLC analysis was performed by using the Shimadzu Prominence UVIVIS (Pump LC20AT, detector SPD $20 \mathrm{~A}$ ) using the column Purospher $5 \mu \mathrm{m}$ (e) C-18, 4.6 X $250 \mathrm{~mm}$ and column temperature $25-28^{\circ} \mathrm{C}$. Chromatography was performed under isocratic conditions, at a flow-rate of $1 \mathrm{ml} / \mathrm{min}$. The mobile phase consisted of a phosphate buffer (PB, $15 \mathrm{mM})$ acetonitrile of $\mathrm{pH}$ 5.0-5.5. The injection volume was $20 \mu \mathrm{l}$ and and the detection wavelength was $228.0 \mathrm{~nm}$. The calibration plot and linearity were determined, and the retention time of BPA was found to be $3.0 \mathrm{~min}$. The limits of detection for the analytes were between 0.122 and $0.468 \mathrm{\mu g} \mathrm{ml}^{-1}$ and the limits of quantification were between 0.360 and $1.418 \mu \mathrm{g} \mathrm{ml}^{-1}$.

\section{Solubility in Phosphate Buffer (0.16 M)}

The aqueous solubility of BPA (1) and its salts (1a-e) was determined in the phosphate buffer $(0.16 \mathrm{M})$ at both $\mathrm{pH} 5.0$ and 7.4 at room temperature. Excess amounts of each salt were added to the phosphate buffer $(0.5 \mathrm{ml})$ individually. The mixtures were stirred and centrifuged at $6000 \mathrm{rpm}$ for $6 \mathrm{~min}$. The concentrations of each of the salts in their saturated solutions were analyzed by HPLC. The $\mathrm{pH}$ of the solutions was held constant throughout the experiment [11].

\section{Apparent Partition Coefficient (Log $P_{\text {app}}$ )}

The apparent partition coefficients (log $P_{\text {app}}$ ) of BPA (1) and its salts (1a-e) were determined at room temperature between 1-Octanol and the phosphate buffer $(0.16 \mathrm{M})$ at pH 5.0 and 7.4 using the shake flask method. 1-Octanol was saturated with the phosphate buffer for $24 \mathrm{~h}$ by stirring vigorously before use. A known concentration of the compound in the phosphate buffer was shaken with a suitable fixed volume of 1-Octanol. After shaking, both the phases were separated by centrifugation at $6000 \mathrm{rpm}$ for $6 \mathrm{~min}$. The concentrations of the compounds in the buffer phase and in the 1-Octanol phase were determined by HPLC [11].

\section{In Vitro Skin Permeation Studies}

In vitro skin permeation studies were performed by using skin from the whole dorsal area of a male Wistar rat in a Franz-type diffusion cell. Skin specimens were rehydrated before being mounted in the diffusion cell. The receptor medium ( $0.05 \mathrm{M}$ phosphate buffer saline solution of $\mathrm{pH} 7.4$ ) was stirred and kept at $37 \pm 1^{\circ} \mathrm{C}$ throughout the study. The compounds (1a-1e) were applied as solutions in the phosphate buffer $(0.05 \mathrm{M})$ at both pH 5.0 and 7.4.

The steady-state flux for BPA (1) and its salts (1a-e) were determined by plotting the cumulative amount of the drug as measured in the receiver phase against time, and dividing the slope of the steady-state position by the surface area of the diffusion cell 
$\left(4.906 \mathrm{~cm}^{2}\right)$. The permeability coefficients $\left(K_{\mathrm{p}}\right)$ for the steady-state delivery were obtained by dividing the steady-state flux $\left(J_{s s}\right)$ by the solubilities of the compounds in the corresponding vehicle [11]. The receiver medium $(0.05 \mathrm{M}$ phosphate buffer saline solution of $\mathrm{pH}$ 7.4) was stirred and kept at $37 \pm 1^{\circ} \mathrm{C}$ throughout the study. The compounds were applied as solutions in the phosphate buffer of $\mathrm{pH} 5.0$ or 7.4. At specified time intervals, aliquots $(0.5 \mathrm{ml})$ were withdrawn from the receiver compartment and replaced with fresh buffer. The drug concentrations were analyzed by HPLC.

\section{Conclusion}

In conclusion, the present study shows that the permeation of BPA through rat skin can be markedly improved by the salt formation approach. Salt formation improves the aqueous solubility and other physicochemical properties essential for drug permeation, and these improvements make these salts promising moieties for the percutaneous delivery of BPA. Increased permeation of BPA coupled with a long half-life and slow clearance from the body can increase local tissue and synovial fluid concentration which is essential for symptomatic relief of rheumatic diseases.

\section{Acknowledgement}

We thank All India Council for Technical Education (AICTE) New Delhi, India for the award of the National Doctoral Fellowship and the M.S. University of Baroda for the award of Junior Research Fellowship to Vijay Pawar.

\section{Authors' Statements}

\section{Competing Interest}

The authors declare no conflict of interest.

\section{Animal Rights}

The institutional and international ethical guidelines for the Care and Use of Laboratory Animals were followed. See the experimental parts for details.

\section{References}

[1] Narumiya S, Sugimoto Y, Ushikubi F.

Prostanoid receptors: Structures, properties, and functions.

Physiol Rev. 1999; 79: 1193-1226.

http://www.ncbi.nlm.nih.gov/pubmed/10508233

[2] Johnson AG. Quinn DI, Day RO.

Non-steroidal anti-inflammatory drugs.

Med J Aust. 1995; 163: 155-158.

http://www.ncbi.nlm.nih.gov/pubmed/7643770

[3] Figueras A, Capellà D, Castel JM, Laorte JR.

Spontaneous reporting of adverse drug reactions to non-stroidal anti-inflammatory drugs. A report from the spanish system of pharmacovigilance, including an early analysis of topical and enteric coated formulations.

Eur J Clin Pharmacol. 1994; 47: 297-303.

http://dx.doi.org/10.1007/BF00191158 
[4] Lichtenstein DR, Syngal S, Wolfe MM.

Nonsteroidal anti-inflammatory drugs and the gastrointestinal tract. The double edged sword.

Arthritis Rheum. 1995; 38: 5-18.

http://dx.doi.org/10.1002/art.1780380103

[5] Hansen TM, Matzen P, Madsen P.

Endoscopic evaluation of the effect of indomethacin capsules and suppositories on the gastric mucosa in rheumatic patients.

J Rheumatol. 1984; 11: 484-487.

http://www.ncbi.nlm.nih.gov/pubmed/6332910

[6] Lee CM, Maibach HI.

Deep percutaneous penetration into muscles and joints.

J Pharm Sci. 2006; 95: 1405-1413.

http://dx.doi.org/10.1002/jps.20666

[7] Mason L, Moore RA, Edwards JE, Derry S, McQuay HJ.

Topical NSAIDs for chronic musculoskeletal pain: systematic review and meta analysis.

BMC Musculoskelet Disord. 2004; 5: 28-38.

http://dx.doi.org/10.1186/1471-2474-5-28

[8] Altman RD.

New guidelines for topical NSAIDs in the osteoarthritis treatment paradigm.

Curr Med Res Opin. 2010; 26: 2871-2876.

http://dx.doi.org/10.1185/03007995.2010.533650

[9] Singh P.

In: Percutaneous penetration as a method of delivery to skin and underlying tissues.

Bronaugh RL, Maibach HI.

New York: Marcel Dekker Inc, 1999: 597-613.

http://dx.doi.org/10.3109/9780203904015-23

[10] Roberts MS, Cross SE.

Percutaneous absorption of topically applied NSAIDs and other compounds: role of solute properties, skin physiology and delivery system.

Inflammopharmacology. 1999; 7: 339-350.

http://dx.doi.org/10.1007/s10787-999-0028-6

[11] Rautio J, Nevalainen T, Taipale H, Vepsäläinen J, Gynther J, Laine K, Järvinen T.

Piperazinyl alkyl prodrugs of naproxen improve in vitro skin permeation.

Eur J Pharm Sci. 2000; 11: 157-163.

http://dx.doi.org/10.1016/S0928-0987(00)00090-7

[12] Yanagimoto G, Hayashi T, Hasegawa T, Seki T, Juni K, Sugibayashi K, Morimoto Y.

Skin disposition of drug after topical application in hairless rats.

Chem Pharm Bull. 1999; 47: 749-754.

http://dx.doi.org/10.1248/cpb.47.749

[13] El-Menshawe SF, Hussein AK.

Formulation and evaluation of meloxicam niosomes as vesicular carriers for enhanced skin delivery.

Pharm Dev Technol. 2013; 18: 779-786.

http://dx.doi.org/10.3109/10837450.2011.598166

[14] Israel B, Garner ST, Thakare M, Elder D, Abney T, Azadi P, Beach JW, Price JC, Ahmed H, Capomacchia AC.

Transdermal permeation of novel n-acetyl-glucosamine/NSAIDs mutual prodrugs.

Pharm Dev Technol. 2012; 17: 48-54.

http://dx.doi.org/10.3109/10837450.2010.513987 
[15] Budai L, Kaszás N, Gróf P, Lenti K, Maghami K, Antal I, Klebovich I, Petrikovics I, Budai M. Liposomes for topical use: a physico-chemical comparison of vesicles prepared from egg or soy lecithin.

Sci Pharm. 2013; 81: 1151-1166.

http://dx.doi.org/10.3797/scipharm.1305-11

[16] Barry BW.

Mode of Action of Penetration Enhancers in Human Skin.

J Controlled Rel. 1987; 6: 85-97.

http://dx.doi.org/10.1016/0168-3659(87)90066-6

[17] Gaur PK, Purohit S, Kumar Y, Mishra S, Bhandari A.

Preparation, characterization and permeation studies of a nanovesicular system containing diclofenac for transdermal delivery.

Pharm Dev Technol. 2014; 19: 48-54.

http://dx.doi.org/10.3109/10837450.2012.751406

[18] Kim BY, Doh HJ, Le TN, Cho WJ, Yong CS, Choi HG, Kim JS, Lee CH, Kim DD.

Ketorolac amide prodrugs for transdermal delivery: Stability and in vitro rat skin permeation studies. Int J Pharm. 2005; 293: 193-202.

http://dx.doi.org/10.1016/j.ijpharm.2005.01.002

[19] Chan SY, Li WPA.

Prodrugs for Dermal Delivery.

Int J Pharm. 1989; 55: 1-16.

http://dx.doi.org/10.1016/0378-5173(89)90270-6

[20] Sloan KB.

Prodrugs for Dermal Delivery.

Adv Drug Del Rev. 1989; 3: 67-101

http://dx.doi.org/10.1016/0169-409X(89)90005-7

[21] Roy SD, Manoukian E.

Permeability of Ketorolac Acid and Its Ester Analogues (Prodrugs) Through Human Cadaver Skin.

J Pharm Sci. 1994; 83: 1548-1553.

http://dx.doi.org/10.1002/jps.2600831106

[22] Fang L, Numajiri S, Kobayashi D, Ueda H, Nakayama K, Miyamae H, Morimoto Y.

Physicochemical and crystallographic characterization of mefenamic acid complexes with alkanolamines.

J Pharm Sci. 2004; 93: 144-154.

http://dx.doi.org/10.1002/jps.10468

[23] Cheong HA, Choi HK.

Enhanced percutaneous absoption of piroxicam via salt formation with ethanolamines.

Pharm Res. 2002; 19: 1375-1380.

http://dx.doi.org/10.1023/A:1020367212307

[24] Sloboda AE, Osterberg AC.

The pharmacology of a fenbufen, 3-(4-biphenyl carbonyl)propionic acid and 4-biphenylacetic acid interesting anti-inflammatory-analgesic agents.

Inflammation. 1976; 1: 415-438.

http://dx.doi.org/10.1007/BF00920340

[25] Dawson M, McGee CM, Vine JH, Nash P, Watson TR, Brooks PM.

The disposition of biphenylacetic acid following topical application.

Eur J Clin Pharmacol. 1988; 33: 639-642.

http://dx.doi.org/10.1007/BF00542502

[26] Hadgraft J, Du Plessis J, Goosen C.

The selection of non-steroidal anti-inflammatory agents for dermal delivery.

Int J Pharm. 2000; 207: 31-37.

http://dx.doi.org/10.1016/S0378-5173(00)00517-2 
[27] Vaile JH, Davis P.

Topical NSAIDs for musculoskeletal conditions.

Drugs. 1998; 56: 783-799.

http://dx.doi.org/10.2165/00003495-199856050-00004

[28] Komatsu T, Sakurada T.

Comparison of the efficacy and skin permeability of topical NSAID preparations used in Europe.

Eur J Pharm Sci. 2012; 47: 890-895.

http://dx.doi.org/10.1016/j.ejps.2012.08.016

[29] Khan MS, Akhter M, Husain A.

Synthesis, biological evaluation and kinetic studies of glyceride prodrugs of biphenyl acetic acid. Ind J Chem B. 2006; 45: 1014-1019.

[30] Hadgraft J, Valenta C.

$\mathrm{pH}, \mathrm{pKa}$ and dermal delivery.

Int J Pharm. 2000; 200: 243-247.

http://dx.doi.org/10.1016/S0378-5173(00)00402-6

[31] Schwenk E, Papa D.

Preparation of aryl aliphatic acids by the modified willgerodt reaction.

J Org Chem. 1946; 11: 798.

http://dx.doi.org/10.1021/jo01176a023 